\title{
UNA APROXIMACIÓN A LA IMPUTACIÓN A TÍTULO DE IMPRUDENCIA EN EL CÓDIGO PENAL CHILENO
}

[An Approach to Bringing Charges on the Basis of Recklessness Under the Chilean Criminal Code]

\section{Ítalo ReYes ROMERO*}

\begin{abstract}
RESUMEN
En este artículo se analiza las disposiciones relacionadas con la falta de cuidado en el Código Penal chileno. Primero se revisa el modelo general de punición de la imprudencia adoptada por nuestra legislación, para luego concentrarse en el rol de los reglamentos y su conexión con la imputación a título de imprudencia. Más tarde, se analizan cada uno de los términos que
\end{abstract}

\section{ABSTRACT}

This article analyzes the provisions on lack of care under the Chilean Criminal Code. Firstly, the general punishment model for recklessness adopted by our law is revised and then we focus on the role of regulations and their connections with bringing charges for recklessness. Subsequently, each term used by the Criminal Code referring to the lack of care, namely, recklessness, negligence,

RECIBIDO el 8 de marzo y APROBADO el 1 de diciembre de 2016

* Abogado, Universidad de Chile. Ex coordinador ejecutivo del Magíster en Derecho con mención en Derecho Penal, Facultad de Derecho, Universidad de Chile. Actualmente realizando estudios de Posgrado en la Universidad de Bonn, Alemania. Correo electrónico: italoreyesromero@gmail.com. El presente artículo es una versión corregida y aumentada de un capítulo de mi memoria de licenciatura titulada "Falta de cuidado y riesgo permitido: una clave de lectura del art. $10 \mathrm{n}^{\circ} 8 \mathrm{del}$ Código Penal" (versión on line http://repositorio.uchile.cl/handle/2250/115478), la cual fue dirigida por el profesor Juan Pablo Mañalich a quien dirijo mis sinceros agradecimientos por sus invaluables comentarios e inagotable paciencia con mi testarudez. 
el Código Penal utiliza para la falta de cuidado, a saber, imprudencia, negligencia, descuido, ignorancia y abandono. Finalmente, se examina la importancia de los adjetivos calificativos que acompañan a los términos utilizados por el legislador y su influencia en la determinación del cuidado debido.

\section{Palabras clave}

Falta de cuidado - exigencia de cuidado - imprudencia - negligencia reglamento. neglect, ignorance and abandonment are analyzed. Finally, the importance of the qualifying adjectives accompanying the terms used by the legislator and their influence in determining the duty of care are reviewed.

\section{KEYWORDS}

Lack of care - duty of care recklessness - negligence - regulations.

\section{INTRODUCCIÓN}

El objetivo de esta investigación está claramente definido: la exégesis de las disposiciones del Código Penal relacionadas con la falta de cuidado. En ese sentido, se pretende sistematizar las disposiciones del Libro II del Código Penal que abren la punibilidad del delito imprudente en atención a los criterios y términos que la misma legislación utiliza. La hipótesis con la cual se emprende dicha empresa es que, bajo una interpretación adecuada, las normas del Código Penal que nos interesan aquí conforman un sistema coherente y que es capaz de responder apropiadamente a ciertas disposiciones con redacciones complicadas. Anticipando el desenlace (spoiler alert), la hipótesis será confirmada.

No obstante, antes de emprender el análisis del Código Penal, se hace necesario exponer brevemente el concepto de falta de cuidado que se defiende en este artículo y que se refleja tanto en el lenguaje como en los criterios utilizados para dar cuenta de la legislación penal chilena.

\section{LA IMPUTACIÓN A TÍTULO DE IMPRUDENCIA}

En términos generales, la imprudencia alude a la comprobación de que, si bien un sujeto no estaba capacitado para evitar una conducta que satisface la descripción típica, sí estaba capacitado para evitar tal situación de incapacidad. Para ello, le resultaba exigible adoptar medidas de precaución contextualmente pertinentes con el objeto de asegurar su capacidad de seguimiento futuro de la norma.

El estudio de la imprudencia se enmarca en el ámbito subjetivo del injusto, en donde se examina la posibilidad de a t $r$ i b u i r una conducta 
que realiza alguna descripción típica a un determinado sujeto. Es decir, comprobar si el autor estaba en posición de seguir la norma al disponer de las capacidades necesarias para la evitación del resultado típico.

Dicho proceso de i $\mathrm{m}$ p u t a c i ó $\mathrm{n}$, que revisa la posibilidad de hacer responsable a un sujeto por una conducta típica, debe diferenciarse categorial y lógicamente del proceso de $s \mathrm{u}$ b s u n c i ó $\mathrm{n}$ realizado en el ámbito objetivo del injusto. La finalidad perseguida por este ámbito objetivo está, por el contrario, en comprobar que la conducta efectivamente ejecutada realiza el contenido proposicional de una determinada norma. Es decir, que la conducta que ejecuta el sujeto es una concreción -de las tantas posibles- de la descripción típica. Y tal proceso se denomina s u b s u n c i ó n porque implica considerar el comportamiento como particularización de la norma. En tal sentido, será esa descripción típica la que determine los elementos relevantes a tener en consideración en la conducta del sujeto.

De tal forma, mediante el proceso de imputación se pone en cuestionamiento la relación entre un comportamiento antinormativo ${ }^{1}$ y un determinado sujeto, de manera que si tal conexión se sostiene, es posible afirmar que tal conducta es $s$ u y a y tiene que tolerar el reproche en su contra por haberla ejecutado. Pues lo interesante de la atribución jurídico penal es que al determinar que el autor contaba con las capacidades necesarias para el seguimiento de la norma, se debe concluir una contradicción entre la voluntad del sujeto, objetivada en su comportamiento, y la voluntad general del ordenamiento, quedando legitimado un reproche en su contra.

Así, la imputación se realiza en virtud de ciertos criterios o reglas que otorgan contenido a la respuesta punitiva por el comportamiento demeritorio y que varían respecto del ámbito de imputación ${ }^{2}$. Estos criterios de imputación aluden al reconocimiento de capacidades que permiten adscribir el comportamiento típico al sujeto³.

El criterio de imputación ordinario o básico está íntimamente rela-

${ }^{1}$ Mañalich, Juan Pablo, Norma e imputación como categorias del hecho punible, en Revista de Estudios de la Justicia 12 (2010), p. 176.

2 HruschKa, Joachim, "Reglas de comportamiento y reglas de imputación", ahora, en el mismo, Imputación y Derecho Penal (Montevideo/ Buenos Aires, B de F, 2009), pp. 14 ss. Véase también, Pérez del Valle, Carlos, La imprudencia en el derecho penal. El tipo subjetivo del delito imprudente (Barcelona, Atelier, 2012) pp. $143 \mathrm{~s}$.

${ }^{3}$ Esto supone que el injusto objetivo de los delitos dolosos e imprudentes análogos es siempre el mismo, pues la diferencia sólo se encuentra en los criterios de imputación subjetiva. En el mismo sentido, véase Pérez del Valle, Carlos, cit. (n. 2), pp. 77 ss., 107 ss. En contra, véase Corcoy, Mirentxu, El delito imprudente. Criterios de imputación del resultado (2a edición, Montevideo/Buenos Aires, BdeF, 2005), pp. 11 ss. 
cionado con el reconocimiento de capa cidad de a c ción : el sujeto presenta las condiciones físicas e intelectuales (cognitivas) con las cuales pudo haber evitado la comisión del hecho ${ }^{4}$. En la medida que esas condiciones implican que el sujeto estuviese en posición física de actuar distinto y que además tuviese el conocimiento suficiente sobre las circunstancias de su actuar, aquí el criterio de imputación relevante es el $\mathrm{d}$ o $\mathrm{o}^{5}$. Entonces quien se comporta dolosamente se encuentra en posición de actuar conforme a la norma respectiva, pues le es evitable tanto física como cognitivamente su infracción, de forma que si el autor ejecuta una acción que realiza la descripción típica está expresando con ello su negativa al seguimiento de la norma, en definitiva, una voluntad de negación del derecho. Por ello, aseveramos que esa conducta es antijurídica ${ }^{6}$.

Lo que nos interesa en esta investigación, empero, es lo que acontece cuando el sujeto carece de la capacidad necesaria para evitar la realización típica. Ello implica que el dolo queda descartado ya que, en el momento relevante, le era imposible ejecutar un comportamiento conforme a la norma. No obstante, aún podemos preguntarnos por la razón por la cual el sujeto carece de la capacidad para evitar el resultado lesivo, es decir, por qué no hay dolo. La pregunta es interesante pues es posible desarrollar acciones que aseguren la capacidad futura, en el sentido que se pretenda

${ }^{4}$ MaÑalich, Juan Pablo, Norma, cit. (n. 1), pp. 179 s. Véase, además, ReYes, Italo, Un concepto de riesgo permitido alejado de la imputación objetiva, en Ius et Praxis año $21, n^{\circ} 1$ (2015), pp. 145 ss, con ulteriores referencias.

${ }^{5}$ KIndHäUSER, Urs, ¿Quées la imprudencia?, ahora, en MaÑAlich (dir.), La ciencia penal en la Universidad de Chile. Libro homenaje a los profesores del departamento de ciencias penales de la facultad de Derecho de la Universidad de Chile (Santiago, Facultad de Derecho, Universidad de Chile, 2013), p. 220. Evidentemente una postura como la señalada asume una posición cognitiva del dolo. Para una revisión tradicional de las teorías al respecto, véase Garrido Montt, Mario, Derecho Penal. Parte Especial (4a edición, Santiago, Editorial Jurídica, 2005), II, pp. 78 ss.; para una revisión dogmática más detallada, véase RAGUÉS I VALLES, Ramón, El dolo y su prueba en el proceso penal (Barcelona, Bosch Editor, 1999), pp. 189 ss.; para una revisión de la jurisprudencia nacional al respecto, véase VAN WEEZEL, Álex, El dolo eventual como espacio de discrecionalidad, en Doctrina y Jurisprudencia Penal, vol. VII (2012). Disponible en: Legal Publishing on line, Cita CL/DOC/1203/2013 [visitado el 24/09/2014], pp. 6 ss.

${ }^{6}$ Aquí puede ser útil acudir al silogismo práctico. Véase KINDHÄUser, Urs, El tipo subjetivo en la construcción del delito, en InDret 4 (2008), pp. 9 s, quien correctamente plantea que el dolo se corresponde con la premisa menor que manifiesta los conocimientos del sujeto sobre el mundo y que eran relevantes para seguir la norma de comportamiento específica. Sólo en atención a esos conocimientos se puede afirmar si el sujeto tenía (o no) el deber de evitar ejecutar una determinada acción, es decir, si libremente decidió contravenir la norma. 
evitar una situación de inevitabilidad. En otras palabras, quien asuma las normas penales como razones para la acción, no sólo puede interesarle evitar la ejecución de acciones que provoquen resultados típicos, sino también evitar una situación en la cual no podrá evitar ese resultado típico. De tal forma, el examen de esta "evitación de la inevitabilidad" se corresponde con el estudio de la imprudencia: el que actúa conforme a cuidado asegura su capacidad para evitar la infracción de la norma ${ }^{7}$.

De tal modo, si el sujeto carece de la capacidad cognitiva necesaria para la evitación de la conducta lesiva no existirá dolo, pero aún podemos imputar extraordinariamente haciendo responsable al autor precisamente por esa ausencia de dolo en los casos en que esa incapacidad no haya sido evitada por el sujeto. Nótese que esta imputación a título de imprudencia sólo es posible cuando no puede afirmarse la imputación a título de dolo porque "solamente cuando algo no está a mi alcance en el momento decisivo puede plantearse si yo soy quizá responsable de que ya no esté a mi alcance"s.

Por tanto, se determina que el sujeto es responsable por el hecho, no basándose en la capacidad que tenía en el momento de su ejecución, sino en la capacidad que podría haber tenido si hubiese actuado previamente atendiendo al seguimiento futuro de la norma. En otras palabras, si el autor se hubiese comportado cuidadosamente entonces podría haber mantenido la capacidad para evitar la infracción de la norma. Y ese cuidado le era exigido normativamente puesto que una acción contraria al cuidado debido también expresa una voluntad de negación del derecho, aunque claramente en un sentido más débil que el dolo. La conducta imprudente manifiesta, por tanto, la aceptación del riesgo de contradicción del derecho por incapacidad de controlar la propia acción futura?

Así entonces, en el contexto de la imprudencia, el criterio de imputación está constituido por la infracción de una exigencia de $\mathrm{c} \mathrm{u} \mathrm{i} \mathrm{d} \mathrm{a} \mathrm{d} \mathrm{o,} \mathrm{puesto} \mathrm{que} \mathrm{si} \mathrm{el} \mathrm{sujeto} \mathrm{pretende} \mathrm{mantener} \mathrm{su} \mathrm{capacidad} \mathrm{de}$ seguimiento futuro de la norma tiene que adoptar las medidas de cuidado

${ }^{7}$ En el mismo sentido, Ovalle, Germán, Imprudencia y cognición, en Doctrina $y$ jurisprudencia penal $n^{\circ} 4$ (2011), p. 5. En un sentido similar, Pérez del Valle, Carlos, cit. (n. 2), pp. 86 s., quien reconoce, por tanto, la radical importancia de la parte especial para una análisis adecuado de la imprudencia.

${ }^{8}$ HruschKa, Joachim, La imputación ordinaria y extraordinaria en Pufendorf, ahora, en El Mismo, Imputación y Derecho Penal (Montevideo - Buenos Aires, B de F, 2009), p. 79.

${ }^{9}$ En un sentido similar, KINDHÄUSER, Urs, ¿Qué es la imprudencia?, cit. (n. 5), p. 222: "Un no-saber también puede expresar un déficit de reconocimiento de la norma, si el correspondiente saber hubiese capacitado al autor para la evitación de la realización del tipo". 
pertinentes ${ }^{10}$. En caso de no adoptar tales medidas, se justifica imputarle el comportamiento típico en cuestión teniéndose por configurado el injusto subjetivo $^{11}$.

\section{LA SANCión DE LA IMPRUdencia EN EL Código PenAL}

La legislación penal puede optar por diversos modelos de punición de la imprudencia en atención a las conductas punibles descritas en los códigos respectivos (en Chile, Código Penal y Código de Justicia Militar) o en otras leyes especiales (por ejemplo, Ley $\mathrm{N}^{\circ} 20.000$ sobre tráfico ilícito de estupefacientes o Ley $\mathrm{N}^{\circ} 19.913$ que sanciona el lavado y blanqueo de activos). En lo que sigue el análisis se circunscribirá exclusivamente al ámbito del Código Penal. Así, un modelo numerus apertus establecerá una regla que permita la sanción a título de imprudencia para cualquier delito descrito en el Código Penal. Éste fue el sistema seguido por el legislador español antes de la reforma del 2005, en donde su art. 565 abría la punibilidad para cualquier delito cometido por imprudencia temeraria ${ }^{12}$. Por el contrario, un modelo numerus clausus dispondrá que la sanción de la

${ }^{10}$ La postura asumida aquí resulta minoritaria en la discusión tradicional sobre la imprudencia, pues entiende que el deber de cuidado tiene relevancia sólo en el injusto subjetivo. Véase, en extenso, sobre la construcción de la exigencia de cuidado desde este punto de vista, REYES, Italo, Sobre la construcción de la exigencia de cuidado, en Política Criminal vol. 10 no 19 (2015), pp. 59 ss. La posición mayoritaria asume que el delito imprudente (en general) tiene un injusto objetivo y subjetivo y que, por tanto, el deber de cuidado también debe analizarse en ambos contextos. Véase, por ejemplo, en la discusión nacional, Rosas, Juan Ignacio, La delimitación del deber de cuidado en la imputación de responsabilidad penal por imprudencia médica, en Doctrina y jurisprudencia penal $\mathrm{n}^{\circ} 5$ (2011), pp. 1 ss.; y FERNÁNDEZ CruZ, José Ángel, El delito imprudente: la determinación de la diligencia debida en el seno de las organizaciones, en Revista de Derecho, vol. XIII (2002), pp. 106 s., 109 ss.; y en la discusión comparada, Corcoy, Mirentxu, cit. (n. 3), pp. 11 ss., 207 ss.

${ }^{11}$ Para la comprensión de la imprudencia, adicionalmente, resulta fundamental el concepto de conexión de contrariedad a deber. Sin embargo, al escapar al foco de esta investigación, no será analizado. Para más detalle sobre la discusión, véase REYES, Italo, Un concepto, cit. (n. 4), pp. 149-150, con ulteriores referencias.

12 El art. 565 del Código Penal español rezaba: "565. El que por imprudencia temeraria ejecutare un hecho que, si mediare malicia, constituiría delito, será castigado con la pena de presidio menor (...)". Los incisos siguientes establecían reglas específicas para la mera imprudencia con infracción de reglamentos, impericia o negligencia profesional y comisión con vehículo de motor. Para más detalle, véase Corcoy, Mirentxu, cit. (n. 3), pp. XXI ss., en donde señala las críticas a este modelo desde el principio de legalidad y de taxatividad; y ETCheberry, Alfredo, Derecho Penal ( $3^{a}$ edición, Santiago, Editorial Jurídica, 1997), I, p. 312 quien se refiere al sistema penal español pre-reforma. 
imprudencia queda vedada a menos que el mismo Código la establezca expresamente. Es el caso del actual Código Penal español que en su artículo 12 establece que "Las acciones u omisiones imprudentes sólo se castigarán cuando expresamente lo disponga la ley"13.

Usualmente el Código Penal chileno es entendido como un modelo numerus clausus en atención al art. 10 no 13: "Están exentos de responsabilidad penal: (...) 13. El que cometiere un cuasidelito, salvo en los casos expresamente penados por la ley". Siendo esto correcto, es necesario tener presente que el Título X del Libro II del Código Penal abre la punibilidad de la imprudencia a todo "crimen o simple delito contra las personas", estos son, los delitos ubicados en el Título VIII del Libro II ${ }^{14}$. Al respecto, la doctrina clásica es unánime en afirmar que sólo pueden sancionarse a título de imprudencia el homicidio simple y las lesiones, pues los demás delitos o bien exigirían expresamente dolo directo (por ejemplo, parricidio o mutilación) o bien su estructura típica no permitiría la comisión por falta de cuidado ${ }^{15}$. Ello puede tener sentido respecto del duelo - es difícil

13 Véase Corcoy, Mirentxu, cit. (n. 3), pp. XXIII ss., en donde explica las ventajas del cambio de sistema del Código Penal español en atención a la sanción excepcional de la imprudencia.

${ }^{14}$ En atención a la "apertura" del Título X del Libro II, Bustos considera que nuestro sistema asume una fórmula mixta: Bustos, Juan, El delito culposo (Santiago, Editorial Jurídica, 2006), p. 19. En el mismo sentido, Fernández CruZ, José Ángel, cit., (n. 10), p. 104, quien sostiene que el Código Penal establecería un sistema de "numerus clausus imperfecto". Para más detalle sobre el tema, véase por todos, Couso, Jaime y Hernández, Héctor, Código Penal comentado. Libro Primero (arts. $1^{\circ}$ a 105). Doctrina y Jurisprudencia (Santiago, LegalPublishing, 2011), pp. 280 ss.

15 Véase, en detalle, Garrido, Mario, cit. (n. 5), I, p. 227, quien justifica la ausencia de punibilidad de los demás delitos basado en que tales delitos o bien exigen elementos subjetivos específicos (por ejemplo, injuria); o bien, exigen un dolo "reduplicado" (por ejemplo, parricidio); o bien, exigen explícitamente dolo directo (por ejemplo, mutilación). En el mismo sentido, Politoff, Sergio - Matus, Jean Pierre - Ramírez, María Cecilia, Lecciones de derecho penal chileno (2a edición, Santiago, Editorial Jurídica, 2004), p. 291 y Etcheberry, Alfredo, Derecho Penal, cit. (n. 10), p. 321. Actualmente el Título X contiene un capítulo 5 bis "De los delitos de tráfico ilícito de migrantes y trata de personas", en donde también se observa la situación ya explicada: o bien se exige un ánimo específico (por ejemplo, en el art. 411 bis con un "ánimo de lucro") o bien el verbo rector u otro elemento del tipo resultan incompatibles con la imprudencia (por ejemplo, "promover" en el art. 411 ter, o la exigencia de "violencia, intimidación, coacción, engaño, abuso de poder..." en el tipo general del art. 411 quater). En todo caso, podría quedar espacio conceptual para defender una interpretación del verbo "facilitar" en el art. 411 ter de una manera compatible con la imprudencia, aunque ello escapa por mucho a la finalidad de esta investigación 
pensar en un duelo imprudente - pero bastante problemático respecto de los delitos contra el honor ${ }^{16}$.

Entonces, para la sanción del delito imprudente, nuestro Código Penal exige que la norma penal haga explícita tal posibilidad pues, de lo contrario, solamente queda disponible la sanción a título de dolo. Sin embargo, de la excepcionalidad de la sanción de la imprudencia no se sigue la imposibilidad de concebirla en aquellos casos en que, legalmente, queda fuera de lugar. Es decir, la imputación extraordinaria reclama pertinencia siempre que se vea excluida la imputación a título de dolo y se verifique la antinormatividad del hecho delictivo. Concurriendo estos requisitos lógicos, la pregunta de si el agente se comportó de acuerdo al cuidado que le incumbía adquiere relevancia jurídico penal y su respuesta negativa permite afirmar la antijuridicidad de su conducta. Que, en fin, no pueda aplicársele pena alguna se deriva ya del principio de legalidad, el cual proscribe cualquier sanción penal no descrita expresamente en la ley.

Esta divergencia entre la siempre posible imputación extraordinaria y la excepcionalidad de sanción del delito imprudente se sustenta en la demarcación entre los conceptos de delito y hecho punible. Mientras el primero se refiere al quebrantamiento imputable de una norma de comportamiento, el segundo atiende a aquel delito que cumple las condiciones que exige el legislador para la imposición de la pena ${ }^{17}$. Así, no todo delito constituye un hecho punible, de forma que no toda imputación extraordinaria que acredita la infracción de la exigencia de cuidado respectiva puede acarrear pena. Por ejemplo, en casos de violación impropia es fácilmente imaginable la falta de cuidado del autor, a pesar de que la ley no reconozca su punibilidad: $A$ accede vaginalmente a $B$, quien tiene 13 años pero $A$ cree que tiene 15 años, de modo que se ve excluido el dolo. Luego, si un sujeto abstracto, dotado de los conocimientos y habilidades de A, se hubiese preocupado en comprobar con mayor exactitud la edad de $B$, cuestión que A no realizó, observamos falta de cuidado. En tal sentido, reconocemos el

${ }^{16}$ Como se plantea previamente, la exclusión de la imprudencia en los delitos contra el honor se basa en la idea generalizada de la doctrina clásica de que se exigiría un animus injurandi para tener por configurada la injuria o calumnia. Sin embargo, una interpretación normativa de dichos delitos debiera prescindir de tal ánimo y, por tanto, abrir la punibilidad a injurias o calumnias imprudentes. La justificación de lo anterior, empero, excede el objetivo de esta investigación. Basta plantear que la posibilidad conceptual queda abierta.

17 Mañalich, Juan Pablo, El delito como injusto culpable. Sobre la conexión funcional entre el dolo y la consciencia de la antijuridicidad en el derecho penal chileno", en Revista de Derecho vol. XXIV (2011), p. 92 
cuasidelito de violación de menor de 14 años, pero al no estar abierta su punibilidad, no se verifica hecho punible alguno.

Ahora bien, cuando el Código Penal permite expresamente la sanción del delito imprudente utiliza determinados conceptos, los cuales deben entenderse como los criterios específicos a tener en cuenta en la imputación extraordinaria. Porque si bien es correcto que todos ellos conforman el género de la fa l t a d e c u i d a d o, del cual se concluye lo antijurídico del comportamiento, el estudio de cada una de las especies permite reconstruir coherentemente la teoría del delito imprudente en el Código Penal. De tal manera, la revisión de la parte especial del Código da cuenta de 18 artículos que imponen una pena por falta de cuidado, donde tres de ellos (arts. 490 a 492) hacen referencia a la generalidad de los crímenes o simples delitos contra las personas, y los 15 restantes se refieren al único delito que describen. Luego, podemos observar cinco conceptos generales que pueden o no verse calificados: i) i m p r u d e n c i a : imprudencia temeraria, mera imprudencia; ii) n e g l i g e n c i a : negligencia inexcusable, negligencia culpable, mera negligencia, mera negligencia con infracción de reglamentos; iii) i g n o r a n c i a : ignorancia inexcusable, ignorancia culpable; iv) d e s c u i d o : descuido culpable; y v) a b a n d o n o. En lo que sigue se presenta una estructura que sistematiza los criterios anunciados. Para evitar prejuzgar sobre la utilización de alguno de los criterios expuestos, cuando nos refiramos en general a todos ellos - o sea, a la infracción de una exigencia de cuidado - usaremos simplemente falta de cuidado.

\section{EL ROL DE LOS REGLAMENTOS: EL CURIOSO CASO DEL ART. 329}

a) No obstante, antes de ello, resulta interesante centrarnos en el art. 329. Esta norma resulta anómala pues es la única disposición que, entre los criterios de imputación relevantes, se refiere autónomamente a la inobservancia de reglamentos, lo cual nos permite analizar de inmediato la conexión entre los reglamentos y la falta de cuidado. La norma reza así: Art. 329. "El que por ignorancia culpable, imprudencia o descuido, o por inobservancia de los reglamentos del camino, que deba conocer, causare involuntariamente accidentes que ocasionen lesión a daño a alguna persona, sufrirá las penas de reclusión menor en su grado minimo y multa de seis a diez unidades tributarias mensuales" (el destacado es mío).

Además de los conceptos de ignorancia, imprudencia y descuido, pareciera que la redacción de la norma señala a la i n o b s e r v a n c i a d e r e g l a m e n t o s como un criterio de imputación independiente y equivalente a los primeros. Esto podría llevar a afirmar que la imputación 
extraordinaria sería totalmente innecesaria si se verificase el quebrantamiento de la normativa del camino respectiva, puesto que se cumpliría una de las exigencias alternativas, siendo superflua la referencia a la falta de cuidado (en la forma de ignorancia, imprudencia o descuido). Ello supondría que debería aplicarse la pena a casos de infracción fortuita de los reglamentos, en donde no es posible imputar extraordinariamente, lo cual resulta inaceptable por configurar una situación de evidente responsabilidad penal objetiva ${ }^{18}$.

b) Sin embargo, el problema es que la función del reglamento no está referida, en caso alguno, al reemplazo de los criterios de imputación. Porque la mera infracción de reglamentos no puede justificar la responsabilidad penal, pues éstos solamente establecen maneras de desarrollar adecuadamente una actividad de acuerdo a lo que ocurre cotidianamente. De tal forma, será posible que ante ciertas situaciones específicas, las normas de cuidado recogidas en los reglamentos no tengan que ser tomadas en cuenta. En aquellos casos lo cuidadoso será determinado en virtud de las reglas generales de la imprudencia, sin necesidad de acudir al reglamento. Lo esencial de la falta de cuidado está en que cumpliéndose las medidas de precaución pertinentes, el sujeto hubiese podido evitar el comportamiento típico ${ }^{19}$, lo cual opera con independencia de una eventual infracción reglamentaria.

De tal forma, la infracción de un reglamento no implica la imprudencia de dicha conducta. El reglamento opera sólo como un indicio de imprudencia, pero en ningún caso la justifica ${ }^{20}$. Piénsese, por ejemplo, en una colisión entre dos vehículos en una autopista a plena luz del día, en donde

18 Ésta es la preocupación de Etcheberry, Derecho Penal, cit. (n. 12), I, pp. 320 s., quien enarbola dos argumentos para evitar la inaceptable conclusión. En primer lugar, en los casos de actividades reglamentadas, el deber de cuidado se concretiza en obligaciones de prudencia especificadas por el reglamento, de modo que su contravención implica, también, un quebrantamiento del deber de diligencia. Luego, en segundo lugar, dado que no existe relación necesaria entre la infracción del reglamento y el quebrantamiento del deber de cuidado, se presentarán casos de infracción reglamentaria fortuita que desconectan ambos conceptos. Con el propósito de asegurar esa conexión, y evadir el reclamo de responsabilidad objetiva, Etcheberry va a exigir, primero, que la misma violación del reglamento sea dolosa o culposa y, segundo, un vínculo causal entre esa inobservancia y el resultado lesivo.

19 Mañalich, Juan Pablo, Condiciones generales de la punibilidad, en Revista de Derecho de la Universidad Adolfo Ibáñez, n ${ }^{\circ} 2$ (2005), p. 412. En el mismo sentido, Corcoy, Mirentxu, cit. (n. 3), pp. 81 ss.

${ }^{20}$ En el mismo sentido, NovoA, Eduardo, Curso de derecho penal (3a edición, Santiago, Editorial Jurídica, 2005), I, pp. 511 s.; CurY, Enrique, Derecho penal, parte general (7a edición, Santiago, Ediciones Universidad Católica, 2005), p. 342; y Bustos, Juan, cit. (n. 11), pp. 54 s.; y Corcoy, Mirentxu, cit. (n. 3), pp. 79 ss. Aparentemente en contra, Fernández CruZ, José Ángel, cit. (n. 10), p. 111 quien 
uno de los conductores no llevaba encendidas las luces del automóvil. A partir del 2007, al circular por rutas interurbanas existe la obligación de tener encendidas las luces del vehículo en todo momento ${ }^{21}$. Sin embargo, si la visibilidad simplemente no fue un factor en la colisión, entonces la infracción reglamentaria carece de relevancia al efecto. A pesar de que está comprobado científicamente que llevar las luces encendidas durante el día reduce las colisiones entre $8 \%$ y $15 \%$, en nuestro caso, la mera infracción del reglamento no alcanza a justificar la imprudencia.

Por el otro lado, sin embargo, el cumplimiento de las exigencias de cuidado precisadas en los reglamentos sí excluye la falta de cuidado. Porque al establecer una determinada medida de precaución como adecuada, el ordenamiento está tolerando una disminución de la capacidad de acción del sujeto, lo cual no excluye la posibilidad de ocasionar un resultado típico, pero que no puede ser imputable al sujeto ${ }^{22}$. Es el caso prototípico de riesgo permitido: legítimamente - porque el ordenamiento lo autoriza - se puede renunciar a exigencias de cuidado superiores, a pesar de que estas exigencias superiores hubieran permitido al sujeto evitar el resultado lesivo. A modo de ejemplo: piénsese en el atropello de un peatón por un vehículo que circula a $50 \mathrm{~km} / \mathrm{h}$, en donde posteriormente las investigaciones policiales comprueban que si el conductor hubiese manejado a 40 $\mathrm{km} / \mathrm{h}$ hubiese podido frenar a tiempo y evitar las lesiones leves del peatón. En este caso, el conductor podría haber evitado el resultado lesivo de haberse comportado más cuidadosamente, lo cual resultar ser la definición de imprudencia. No obstante, el ordenamiento jurídico establece, en los reglamentos correspondientes, medidas de precaución que implican una ponderación de riesgos y beneficios de un determinado comportamiento, de modo que su cumplimiento impide la afirmación de imprudencia ${ }^{23}$. El conductor en nuestro ejemplo, entonces, tendría que defenderse aludiendo a que es la misma ley del tránsito la que le permite circular a una velocidad

indica, sin reservas, que la infracción de las normas extrapenales que fijan el riesgo permitido operaría como una fuente de la imprudencia.

${ }^{21}$ El Decreto Supremo No 181/2006 del Ministerio de Transportes y Telecomunicaciones establece: "Los vehículos motorizados, cuando circulen por rutas interurbanas, incluso cuando estas rutas atraviesan zonas urbanas, deberán hacerlo con sus luces de circulación diurnas encendidas; en caso de no contar con dichas luces, deberán hacerlo con sus luces bajas encendidas".

${ }^{22}$ Mañalich, Juan Pablo, Condiciones, cit. (n. 20), p. 412. Véase, también, ReYEs, Italo, Un concepto, cit. (n. 4), pp. 153 ss.

${ }^{23}$ Reyes, Italo, Un concepto, cit. (n. 4), p. 154. En el mismo sentido, Fernández Cruz, José Ángel, cit. (n. 10), p. 112. Sobre la discusión, además, véase Couso, Jaime y HernÁNDEZ, Héctor, cit. (n. 14), pp. $112 \mathrm{~s}$. 
máxima de $60 \mathrm{~km} / \mathrm{h}$, de modo que resulta totalmente contradictorio que se le llegase a sancionar por esa misma circunstancia ${ }^{24}$.

Aún así, las normas de cuidado expresadas en reglamento son resultado del aprendizaje histórico indicativo de la conducta adecuada para la inmensa mayoría de los casos. En otras palabras, de la imposibilidad que la infracción de normas de cuidado reglamentarias fundamenten responsabilidad no se deriva su inutilidad: operan como un indicio del actuar imprudente. Si bien no existe relación necesaria entre la infracción del reglamento y la infracción de la exigencia de cuidado, su contingente pero habitual conexión permite suponer falta de cuidado ante el quebrantamiento del reglamento, dejando espacio, en todo caso, para el argumento en contrario. De ahí que la reglamentación contenga simplemente "un llamado de atención” respecto de una medida de precaución general, pero que puede ser sustituida por otra medida equivalente ${ }^{25}$.

No obstante, entendiendo que los reglamentos operan como formulaciones normativas cotidianas, existirán situaciones excepcionales en donde perderán toda su eficacia como solución anticipada a ponderaciones de riesgos cancelándose su efecto de exoneración como riesgo permitido. Esto sucede específicamente en contextos de colisiones de infracciones reglamentarias en donde el cumplimiento de las medidas de precaución no impide la imputación a título de imprudencia. Veamos dos ejemplos que evidencian el problema. Primero, piénsese, en un carnaval que se celebra dentro de la ciudad ante lo cual, gradualmente, la gente participante comienza a ocupar las calle aledañas. En ese caso, un conductor prudente tendrá que aumentar las medidas de precaución ante la posibilidad cierta de que personas crucen intempestivamente la calle lo que se traducirá, por ejemplo, en la detención ante todo cruce, a pesar de tener preferencia de paso, y en una disminución considerable de la velocidad. De producirse un atropello, el conductor no se podrá defender señalando que conducía bajo la velocidad máxima permitida, pues en este contexto excepcional las medidas de precaución establecidas por las Ley del Tránsito pierden

${ }^{24}$ En el mismo sentido, aunque sin identificar la situación como riesgo permitido, ETCHEBERry, Alfredo, Derecho penal, cit. (n. 12), I, p. 316, quien igualmente previene que los reglamentos - "conociendo sus propios límites" - establecen una "cláusula de escape”, en donde lo relevante siempre será la evitación de resultados dañosos. En el caso de la Ley del Tránsito, el art. 114, luego de indicar que las normas de la ley son obligatorias, señala que "los conductores están obligados a mantenerse atentos a las condiciones de tránsito del momento".

25 Bustos, Juan, cit. (n. 14), p. 54. En el mismo sentido, Corcoy, Mirentxu, cit. (n. 3), pp. 86 s., en donde plantea que la norma penal siempre prevalece sobre el reglamento, pero que este último es útil para concretar el deber objetivo de cuidado. 
relevancia. De tal modo, todo el incremento de cuidado no queda regulado por dicha normativa sino que deriva de la voluntad de evitar quedar en una situación en la que sea inevitable un accidente, o sea, simplemente de un comportamiento conforme a cuidado.

Un segundo ejemplo nos enfrenta a un caso más complejo. Una costumbre muy arraigada en nuestro país consiste en el comportamiento vehicular frente a los cortejos fúnebres. Si bien esta situación no está regulada por ningún reglamento ${ }^{26}$, todos los conductores permiten que los vehículos en cortejo fúnebre circulen a baja velocidad e incluso cruzando semáforos en rojo. Si un ciclista que transita por una vía perpendicular a la calle en que circula el cortejo fúnebre, el cual - de acuerdo a la costumbre - lo hace a baja velocidad y traspasando el semáforo en rojo, colisiona con un vehículo del mismo cortejo, entonces la pregunta es quién se comportó imprudentemente. Y dado el contexto excepcional de los hechos, el ciclista no podría defenderse acudiendo a la Ley del Tránsito al indicar que cumplió con todas sus disposiciones pues el caso está más allá del ámbito de aplicación de dicha normativa. La solución tiene que estar en la evaluación concreta de la situación, en donde perfectamente puede concluirse que el ciclista debió circular en forma más atenta percatándose oportunamente de la situación para disminuir su velocidad o detener su circulación. El cumplimiento de las medidas de precaución establecidas en el reglamento (Ley del Tránsito) no configura aquí un riesgo permitido, puesto que la excepcionalidad de escenario exige no tomar en cuenta la ponderación realizada por el reglamento (pues es un caso paradigmáticamente no cotidiano, o sea, no tenido en consideración al momento de formular el reglamento) construyéndose el nivel de cuidado de acuerdo a las reglas generales ${ }^{27}$.

c) Ahora bien, clarificada la función auxiliar y nunca justificante de los reglamentos, queda aún por resolver el problema del art. 329. Y la respuesta es problemática porque de una lectura superficial pareciera confirmarse que la mera inobservancia de los reglamentos del camino permite validar la sanción penal sin necesidad de recurrir a un criterio

${ }^{26}$ La Ley del Tránsito sólo se refiere a los cortejos fúnebres en su artículo 127 en donde regula la distancia entre vehículos que transitan por la misma vía, indicándose que, en caso de circular en caravana, igualmente debe mantenerse una distancia suficiente para el adelantamiento por otros vehículos. Luego se plantea: "Esta disposición no se aplicará a los cortejos fúnebres".

${ }^{27}$ Esto no quiere decir que en estas situaciones excepcionales no opere el riesgo permitido, sino que las medidas de cuidado establecidas en el reglamento no pueden ser sensatamente aplicadas a casos totalmente fuera de su aplicación cotidiana. El riesgo permitido se mantiene igualmente como la contracara de la exigencia de cuidado. Para más detalle, véase ReYes, Italo, Un concepto, cit. (n. 4), pp. 152 ss. 
de imputación. No basta, a este respecto, la referencia de la disposición a que esos reglamentos $\mathrm{deb}$ a n e r conocidos por el autor, pues sigue siendo perfectamente posible que éste infringiese, de manera completamente fortuita, un reglamento que deba conocer. Por ejemplo, imaginemos que la reglamentación de la conducción de ferrocarriles indica que la velocidad máxima a la que se puede conducir la máquina al acercarse a un cruce es de $40 \mathrm{~km} / \mathrm{h}$, pues así se tiene tiempo suficiente para frenar en caso de observar algún obstáculo en la vía. Sin embargo, el maquinista A conduce a $60 \mathrm{~km} / \mathrm{h}$ y en uno de esos cruces atropella y causa la muerte de B. Pero luego se comprueba que, dado el mal estado de los frenos de la máquina y el estado de embriaguez de B, aún conduciendo a $20 \mathrm{~km} / \mathrm{h}$ hubiese causado su muerte. En este caso habría que negar la imprudencia de A basado en la falta del vínculo de contrariedad a deber, ya que aún cumpliendo con el cuidado exigido igualmente causaba el resultado lesivo, fracasando la imputación extraordinaria ${ }^{28}$. No obstante, en razón del art. 329 , aún sería posible castigar a A porque se cumplen con los requisitos que la misma norma exige: se causa involuntariamente un accidente, el accidente ocasiona daño o lesión a una persona y, lo más importante, el comportamiento infringe el reglamento respectivo. La sanción que se le impondría a A sería, a todas luces, un caso de responsabilidad objetiva, lo que contradice directamente el principio de culpabilidad. Se entendería como una forma de versari in re illicita, ya que al encontrarse el autor en una situación ilícita- en nuestro caso conducir sobre la velocidad permitida- tiene que responder por todas las consecuencias de dicha situación, aun si son meramente fortuitas ${ }^{29}$.

Si bien no podemos negar que, en la época de aprobación de nuestro decimonónico Código Penal, la intención de los legisladores consistiera precisamente en sancionar estos comportamientos en la forma de una responsabilidad objetiva, tal conclusión tiene que volverse inaceptable para nosotros. La pena sólo puede imponerse al comprobar la culpabilidad del autor, lo que implica corroborar su capacidad - primaria y secundaria - en la evitación de la infracción de la norma. Sin la satisfacción de algún criterio de imputación, por tanto, la pena simplemente queda fuera de alcance ${ }^{30}$.

${ }^{28}$ Véase supra, nota 11.

${ }^{29}$ Para revisar las particularidades del versari, véase ETCHEBERRY, Alfredo, Derecho penal, cit. (n. 12), I, p. 328.

${ }^{30}$ El principio de culpabilidad ha sido reconocido por la Corte Suprema en la ampliamente estudiada sentencia de fecha 4 de agosto de 1998 (SCS, 04.08.1998, Rol 1338-98, Contra Castro Muñoz, Revista Fallos del Mes n 477, agosto 1998). Allí la Corte Suprema reconoce que la culpabilidad es un presupuesto de la responsabilidad penal y que está categóricamente reafirmada por la Constitución en la forma de 
Por lo tanto, tenemos que entregar una interpretación diferente que haga plausible al art. 329 a la luz del principio de culpabilidad. Y la solución estaría en concentrarse en la preposición que vincula la causación del accidente con la inobservancia del reglamento, a saber, por. Pues el legislador no utiliza la preposición con, la cual implica un acompañamiento de dos elementos, sino que por, la cual conlleva una relación de medio o modo de los elementos planteados. Así, una interpretación del art. 329 que acepte la responsabilidad objetiva estaría entendiendo ambos elementos - la causación del accidente y la inobservancia del reglamento - de una manera completamente independiente entre sí, lo cual no se correspondería con la semántica específica de la disposición. Por tanto, la infracción del reglamento no es el único elemento que se tiene en consideración para dar por satisfecho este delito imprudente sino que es el medio o modo por el cual se produce el accidente.

Luego, es posible entender que el art. 329, en su conjunto, hace referencia a la punibilidad de una forma de comportamiento imprudente. Es decir, la inclusión legislativa de la infracción del reglamento entre los criterios relevantes del art. 329 para la sanción de la falta de cuidado en los casos en cuestión, se enmarca dentro de los estándares de esa falta de cuidado ${ }^{31}$. De ahí se puede entender que el elemento de inobservancia de reglamento se vincula más bien con la manera en que se reconoce la imprudencia en la forma de una referencia explícita a la conexión de riesgo o de contrariedad a cuidado ${ }^{32}$. En otras palabras, la disposición está haciendo manifiesto que si el sujeto hubiese observado el reglamento pertinente entonces tendría que haber estado en posición de evitar el resultado típico.

una prohibición de presunción de derecho de la responsabilidad penal: " 8 o. Que lo expuesto en el considerando precedente está ahora categóricamente reafirmado por el artículo 19 No $^{\circ}$ inciso $6^{\circ}$ [actual $7^{\circ}$ ] de la Constitución Política de la República, el cual prohíbe presumir de derecho la responsabilidad penal. En efecto, de acuerdo con la mejor doctrina la "culpabilidad" es un presupuesto indispensable de la "responsabilidad" penal; y si, a su vez, la culpabilidad requiere la posibilidad de obrar en otra forma (libertad de decisión) la cual, por su parte, presupone la conciencia de la ilicitud, resulta inconcuso que en el presente se encuentra constitucionalmente prohibido presumir de derecho el conocimiento de lo injusto". A la misma conclusión ha llegado el Tribunal Constitucional en su sentencia Rol 1584-2009, en donde se describen los delitos calificados por el resultado como contrarios al principio de culpabilidad.

31 En un sentido similar, Etcheberry, Alfredo, Derecho penal, cit. (n. 12), I, pp. 320 s., quien plantea que "el deber de cuidado, que es general y amplio, aparece en estos casos precisado a través de ciertas obligaciones de prudencia que especifican los reglamentos".

${ }^{32}$ Véase supra, nota 11. 
De ahí que la infracción meramente fortuita de la reglamentación no podría entenderse como una especificación de la norma, ya que el concepto de inobservancia de reglamento escaparía al contenido de falta de cuidado general planteada por dicho artículo. Y como la infracción fortuita del reglamento no es un caso de falta de cuidado, entonces quedaría fuera de los límites de la descripción típica.

En tal sentido, por medio de una interpretación restrictiva de la disposición, basada en la preposición p o r , excluiríamos cualquier referencia a la responsabilidad objetiva porque haríamos depender la infracción del reglamento a la falta de cuidado, de manera que el reglamento volvería a cumplir una función meramente indiciaria de la imprudencia. La causación del accidente $\mathrm{p}$ o $\mathrm{r}$ la inobservancia del reglamento explicitaría tanto la importancia de una reglamentación de las medidas de precaución en este contexto como la necesidad de que el sujeto hubiese podido evitar el resultado típico de haberlo seguido ${ }^{33}$.

\section{LOS CONCEPTOS DE IMPRUDENCIA Y NEGLIGENCIA EN EL Código Penal}

Propuesta una solución sobre las dificultades teóricas del art. 329, ahora nos haremos cargo de los dos términos más utilizados por el Código Penal en la apertura de la punibilidad por falta de cuidado, a saber, imprudencia y negligencia. Por ahora, se prescindirá de la discusión sobre los calificativos ${ }^{34}$.

a) El desafío, entonces, está en proponer un criterio para la clasificación entre imprudencia y negligencia que resulte coherente con la regulación legal. Así, al examinar los artículos 490 y 491 como normas paradigmáticas que utilizan ambos conceptos, es posible observar una diferencia importante en el contenido de ambas disposiciones. Pues mientras el art. 490 habla de la i m prudencia te meraria, en el contexto de los hechos que si mediara dolo constituirían un delito contra las personas; el art. 491 inc. $1^{\circ}$ se refiere a la n e g li g e n c i a cul pable, en el contexto de la praxis médica. Por tanto, de acuerdo al diferente ámbito de aplicación de estas normas, se puede sostener el siguiente criterio: la negligencia se

${ }^{33}$ Esta solución se asimila a las exigencias adicionales que planteara ETCHEBERRY, Derecho penal, cit. (n. 12), I, p. 321, para evitar casos de versari, quien termina requiriendo dolo o culpa respecto de la infracción del reglamento. El punto a favor de nuestra interpretación es que no necesita modificar la estructura básica de la imputación a título de imprudencia en la disposición, pues la preposición por permite conectar la inobservancia del reglamento con la falta de cuidado.

${ }^{34}$ La discusión sobre calificativos se realizará en el apartado 7: "El aporte de los calificativos a la imputación a título de imprudencia”. 
refiere a contextos en donde existen exigencias especiales de conducta para un grupo preciso de sujetos, y la imprudencia a contextos en donde sólo existen exigencias generales. En palabras de Bustos, la imprudencia estaría referida a cualquier ámbito de relación de una persona y la negligencia solamente a un ámbito específico de su actuar ${ }^{35}$.

Lo relevante es que la calidad del sujeto activo afecta la determinación de las exigencias de cuidado en un contexto preciso de actuación. Tratándose de la negligencia, por tanto, "los estándares de cuidado están definidos en función al desempeño de determinados roles" ${ }^{36}$. Es evidente que a un médico le exigiremos que se comporte de acuerdo a la praxis médica, lo cual no acontecerá respecto de un otro no médico, de modo que si este último intentase salvar a alguien y no lo consiguiese porque no ejecutó una técnica profesional precisa, no concluiríamos reproche alguno basado en el no ejercicio de una capacidad inalcanzable a su efecto (pero quizás sí reprocharíamos que no condujese al lesionado a un hospital). Sin embargo, lo que le exigimos al médico no depende exclusivamente del estatus especial del sujeto sino de que, en el contexto concreto de actuación, esas exigencias sean pertinentes. Ello implica que, para la falta de cuidado, la cualificación de médico solamente es relevante allí donde el contexto lo hace relevante, de modo que, cuando no lo sea, quedará sometido a las exigencias de cuidado generales. Es cierto que lo anterior parece baladí, pero resulta fundamental para desconectar el estatus especial del sujeto

35 Bustos, Juan, cit. (n. 14), p. 49. Adicionalmente, en la doctrina chilena clásica existen otras dos opiniones sobre el significado de los términos imprudencia y negligencia. La primera plantea que no existen diferencias relevantes entre los conceptos pues apuntan a la misma idea de falta de cuidado. Véase al respecto, Cury, Enrique, cit. (n. 21), p. 345 y Garrido Montt, Mario, cit. (n. 5) p. 226. La segunda teoría - cuya expresión más desarrollada está en ETCHEBERRY, Alfredo, Derecho penal, cit. (n. 12), I, p. 319 - entiende que la imprudencia se caracteriza por el afrontamiento (general) de un riesgo, en donde el sujeto pudo haber evitado el resultado lesivo desplegando menos actividad que la empleada; mientras que la negligencia se traduciría en una falta de actividad, en donde el resultado se hubiera evitado desplegando más actividad que la desarrollada. En un sentido similar a Etcheberry, véase Labatut, Gustavo, Derecho penal (9a edición, Santiago, Editorial Jurídica, 1990), I, p. 126 y NovoA, Eduardo, cit (n. 21) p. 508. No obstante, de la necesidad de desplegar más o menos actividad no se sigue ninguna consecuencia teórica relevante porque la exigencia de cuidado consistirá siempre en realizar o dejar de realizar algo dependiendo del contexto preciso en el que se desenvuelva el sujeto y del comportamiento que está realizando. Limitar la falta de cuidado a la realización de más o menos actividad de acuerdo al término usado por el legislador parece no ser la mejor alternativa.

${ }^{36}$ Mañalich, Juan Pablo, Condiciones, cit. (n. 20), p. 416. 
con la determinación del cuidado exigido: ese estatus carece de relevancia por sí solo, es el contexto el que se la otorga.

De tal modo, la imprudencia está referida a exigencias de cuidado generales y la negligencia a exigencias de cuidado específicas, es decir, la primera se refiere a cualquier sujeto y la segunda a un sujeto que cuenta con un estatus especial que, de acuerdo al contexto, resulta relevante en la determinación del cuidado debido ${ }^{37}$.

Ahora bien, además, este criterio de diferenciación entre imprudencia y negligencia resulta coherente con el resto de la regulación legal, lo que se comprueba revisando las normas que hacen referencia a la negligencia y la cualificación del sujeto activo. La siguiente tabla muestra los cuasidelitos en donde no existen dudas entre la referencia a la negligencia y el estatus especial del sujeto que la misma norma explicita.

\section{Norma Capítulo Referencia expresa Sujeto especial}

Art. 224 Prevaricación (..) cuando por negligencia o ignorancia inexcusable dictaren sentencia Miembros de tribunales de justicia o manifiestamente injusta en causa criminal

Art. 225 Prevaricación (...) cuando por negligencia o ignorancia inexcusable (...) fiscales judiciales

Art. 228

Prevaricación

Si la resolución o providencia manifiestamente injusta la diere por negligencia o ignorancia inexcusable (...)

Miembros de tribunales de justicia o fiscales judiciales

Funcionario público no perteneciente al orden judicial

37 Nótese que la referencia de la negligencia a exigencias de cuidado específicas contextualmente relevantes es independiente de la asunción de un modelo individualizador que incorpora en la construcción del deber de cuidado a las capacidades y conocimientos especiales del sujeto. Pues con la referencia a negligencia, el legislador está indicándole al intérprete que haga hincapié en el rol del sujeto para determinar la infracción de la exigencia correspondiente. Véase, al respecto, REYES, Italo, Sobre la construcción (n. 10), pp. 82 ss.; y VAN WeEZEL, Álex, Parámetros para el enjuiciamiento de la infracción al deber de cuidado en los delitos imprudentes, ahora, en el mismo, Limites de la imputación penal. Estudios 2000-2010 (Bogotá, Universidad Externado de Colombia, 2011), pp. 136 ss., en donde se critica el modelo de los conocimientos promedios por ser insuficiente al momento de imputar a un sujeto. 
$\begin{array}{ll}\text { Art. } 229 \text { Prevaricación } & \text { (..) que por malicia o } \\ & \text { negligencia inexcusables } \\ & \text { y faltando a las obligacio- } \\ & \text { nes de su oficio, no pro- } \\ & \text { cedieren a la persecución } \\ & \text { (..) }\end{array}$

Art. 234 Malversación El empleado público que, de caudales por abandono o negligenpúblicos cia inexcusables, diere ocasión a que se efectúe por otra persona la substracción (...)

Art. 243 Infidelidad en El guardián que por su la custodia de negligencia diere lugar al documentos delito (...)

Art. 289

Art. 491
Delitos relativos a la salud animal y vegetal

\section{De los Cuasi-} delitos
Funcionario público no perteneciente al orden judicial

Funcionario público

Guardián (funcionario público que tiene a su cargo la custodia de papeles sellados por la autoridad)

Tenedor o encargado de las especies animales o vegetales

Médico, cirujano, farmacéutico, flebotomiano o matrona cia culpable en el desempeño de su profesión (...)

En todo caso, que la negligencia se relacione con el desempeño de un rol especial por parte del sujeto activo no implica, en ningún caso, que tales normas de sanción establezcan necesariamente delitos especiales. Porque un delito especial consiste en el quebrantamiento de una norma especial, la cual se caracteriza porque el lugar del destinatario de la misma sólo puede corresponder a alguien que ostenta un determinado estatus. Sin embargo esa cualificación se tiene que observar necesariamente en la descripción típica que señala el comportamiento prohibido o mandado. De tal manera, el reconocimiento de un delito como especial se sitúa en el análisis del llamado tipo objetivo, porque la intervención de un sujeto especial es un elemento exigido por la propia descripción típica para dotar de relevancia jurídico penal a la conducta desempeñada ${ }^{38}$. Y entendien- 
do que las reglas que permiten la punibilidad de la falta de cuidado no pueden ser entendidas como normas de comportamiento adicionales ${ }^{39}$, sino simplemente como criterios para el proceso de imputación, es que la calificación de delito especial queda fuera de lugar. Porque la norma de comportamiento infringida siempre es la misma tanto en la imputación ordinaria (dolo) como en la extraordinaria (falta de cuidado). Por lo tanto, la utilización del término negligencia indica que la configuración de la exigencia de cuidado toma en consideración el estatus del sujeto especial, no que sólo pueda ser cometida por ese sujeto especial.

b) Por el otro lado, en relación con la imprudencia, el criterio se ve satisfecho claramente respecto del art. 490, que sanciona a "el que por imprudencia temeraria ejecutare un hecho que, si mediara malicia, constituiria un crimen o simple delito contra las personas", y art. 333, que castiga a "el que por imprudencia rompiere los postes o alambres de la línea telefónica". Tales normas ratifican el argumento de que la noción de imprudencia hace referencia a exigencias (generales) de cuidado posibles de infringir, en principio, por cualquiera. Es decir, la configuración de la exigencia de cuidado no requiere tomar en consideración el estatus del autor.

Ahora bien, ¿para qué es útil distinguir los conceptos de imprudencia y negligencia en la forma señalada? Lo primero es enfatizar que ambas son formas de falta de cuidado y, por tanto, formas de infracción de una exigencia de cuidado. De ahí que no se observa diferencia alguna en la construcción del estándar de cuidado. Una ventaja que ofrece la clasificación es que para concluir que una conducta es negligente existe una alta probabilidad de recurrir a reglamentos que determinen la manera adecuada de desempeño de la actividad específica. Por el contrario, como los casos de imprudencia aluden a exigencias generales, comúnmente carecerán de referencia a normas técnicas guiándose por la configuración ordinaria del cuidado debido. Nótese que la conexión entre la negligencia y la regla-

“determinados delitos culposos sólo pueden cometerlos algunos sujetos calificados, como la malversación culposa, donde se exige en el autor la calidad de funcionario público". Con ello, implícitamente, diferencia el ámbito lógico en que hablamos del delito especial y el ámbito en que hablamos de imprudencia.

39 Mañalich, Juan Pablo, Condiciones, cit. (n. 20), p. 415. También sobre el tema, Reyes Romero, Italo, El cuasidelito con resultado múltiple, en El derecho penal como teoría y como práctica. Libro en homenaje al profesor Alfredo Etcheberry (Santiago, Thomson Reuters, 2016), Capítulo 3.C. En extenso sobre la evolución de la doctrina finalista que postula el quebrantamiento de normas diferentes para delitos dolosos e imprudentes análogos y la crítica al respecto, véase FEIjOO, Bernardo, Resultado lesivo $e$ imprudencia. Estudios de los limites de la responsabilidad penal por imprudencia y el criterio del "fin de protección de la norma de cuidado" (Barcelona, Bosch, 2001), pp. 41, 84 ss. 
mentación de las medidas de precaución no es necesaria sino simplemente de probabilidad. Es decir, como la negligencia se conecta con un ámbito específico de relación es factible que la autoridad o un grupo autoritativo de aquellos profesionales hayan entregado directivas de comportamiento útiles para la determinación del cuidado debido.

Pero además, los contextos que precisan exigencias de cuidado especiales implican un conocimiento y capacidad mínima que habilita para el desempeño de la actividad, puesto que el sujeto desempeña un rol social específico que se toma en cuenta en la definición de la falta de cuidado. De tal modo, cualquiera que carezca de tales conocimientos y capacidades mínimos simplemente debe omitir ejercer la actividad; de lo contrario, surge la culpa por asunción. En tal sentido, el desempeño del rol limita, ab initio, los sujetos que pueden cometer negligencia, porque restringe los participantes a aquellos con un mínimo de habilidades. Aquello no ocurre en la imprudencia, en la cual en principio cualquier sujeto puede quebrantar la exigencia de cuidado respectiva.

c) La distinción opera sin mayor dificultad en normas que utilizan solamente uno de los criterios. Sin embargo, los casos difíciles se corresponden con normas que señalan, al mismo tiempo, a la imprudencia y a la negligencia pues, a primera vista, los conceptos parecen excluyentes entre sí: o hay exigencias generales o hay exigencias específicas de cuidado. Estas "normas problemáticas" pueden relacionarse tanto con delitos comunes como delitos especiales.

En el primer caso - delitos comunes que hacen referencia conjunta a imprudencia y negligencia - encontramos a los artículos 317, 329 y 492. En ninguna de esas normas se especifica al sujeto activo pues se hace alusión a "el que". Como la referencia al sujeto activo es amplísima se está aludiendo a cualquier sujeto, incluso a aquellos que cuentan con un estatus especial. Por tanto, para evitar excluir exigencias de cuidado específicas dependientes de la cualificación del sujeto activo, se incorpora el concepto de negligencia.

Metafóricamente puesto, el legislador está indicando que, primero, todo sujeto debe cumplir exigencias generales de cuidado y, segundo, quien tiene un estatus que resulta relevante en el contexto de actuación, tiene que cumplir con las exigencias específicas pertinentes. Por ejemplo, el art. 317 permite la punibilidad a título de imprudencia temeraria o mera negligencia con infracción de reglamentos del art. 315, el cual plantea "el que envenenare o infectare comestibles, aguas u otras bebidas destinados al consumo público (...)". Si, por ejemplo, A derrama cantidades exorbitantes de cloro en un pozo destinado al consumo público con el objeto de limpiarlo pero termina envenenándolo, actúa de manera imprudente pues infringe 
exigencias generales de cuidado, a saber, leer las indicaciones del uso de cloro. Sin embargo, supongamos que A es ahora un funcionario público dedicado a la fiscalización de pozos de agua, quien por cansancio no realiza todos los exámenes químicos a un determinado pozo, ocasionando lesiones en la población. En este último caso, sólo recurriendo a exigencias de cuidado específicas de A como funcionario público podríamos afirmar falta de cuidado, en la forma de negligencia. De tal forma, el art. 317 recurre tanto a la imprudencia como a la negligencia con el propósito de brindar la mayor protección posible al bien jurídico, incorporando explícitamente toda exigencia de cuidado que pueda ser pertinente al caso ${ }^{40}$.

En tal sentido, las normas de sanción que se refieren simultáneamente a imprudencia y negligencia, con alusión a un sujeto activo general, brindan una protección explícitamente amplia al bien jurídico respectivo pues la infracción de cualquier exigencia de cuidado permite dar por satisfecha la imputación extraordinaria. Más que una incorporación que modifique los resultados de la imputación es una declaración del legislador: ningún descuido es tolerado. No obstante, esto no implica que una norma que carezca de la referencia a ambos conceptos implique una desprotección del bien jurídico, sino que dado el contenido de la norma no es necesario proveer especial protección. Por ejemplo, el art. 333 - que sanciona a quien por imprudencia rompa postes o alambres de una línea telegráfica - no necesita acudir a la negligencia pues exigencias de cuidado generales son suficientes para reconocer el resultado típico. Alguna habilidad o conocimiento de un sujeto especial no reclama relevancia en la evitación de la infracción inevitable de la norma.

En segundo lugar, encontramos al (único) delito especial que señala conjuntamente imprudencia o negligencia. Es el caso del art. $150 \mathrm{~A}$ inciso final que sanciona el (cuasi)delito de torturas, restringiendo el sujeto activo a los funcionarios públicos. El párrafo final señala: "Si de la realización de las conductas descritas en ese articulo resultare alguna de las lesiones previstas en el artículo 397 o la muerte de la persona privada de libertad, siempre que el resultado fuere imputable a negligencia o imprudencia del empleado público (...)”. Así, tanto la negligencia como la imprudencia están referidas a un sujeto cualificado. Esto podría ser un problema al asumir una relación inmediata entre el estatus del sujeto activo y el concepto de negligencia, entendiendo que la conducta de ese sujeto especial - en este caso, un

${ }^{40}$ Nótese que de no existir la referencia a la negligencia en el art. 317, entonces la acción de A (experto químico) tendría que subsumirse bajo la imprudencia temeraria, lo que parece argumentativamente más complejo. 
funcionario público - sólo puede estar relacionada con las exigencias de cuidado que se derivan de su investidura.

No obstante, ya planteamos que tal argumento es erróneo porque el estatus del sujeto sólo adquiere relevancia en la determinación del cuidado debido cuando el contexto de actuación así lo señala. De ahí que una persona con un título de medicina no carga con el estatus de médico en todo ámbito en que se desenvuelve, sino que sólo en aquellos ámbitos en que resulta relevante ese estatus. Lo mismo pasa, entonces, con la condición de funcionario público: quien ha sido investido no se desempeña como tal en todos los casos, máxime cuando la categoría de funcionario público es sumamente amplia. Si lo especial del sujeto activo sólo es relevante en ámbitos precisos, entonces en los demás ámbitos el sujeto mantiene el estatus pero ya carece de relevancia para la determinación de exigencias específicas de cuidado, sometiéndose simplemente a las exigencias de cuidado generales.

Por tanto, el art. $150 \mathrm{~A}$ adquiere sentido pues, siendo un delito especial que limita el sujeto activo a los funcionarios públicos, los compele a desempeñar no sólo las exigencias de cuidado que se derivan de su cargo y que son relevantes en una determinada situación, sino también las exigencias de cuidado a que cualquier persona está obligada. El criterio se aclara examinando dos ejemplos: A es un siquiatra del Hospital Siquiátrico, el cual ha sido investido como funcionario público, y que cree colaborar con una cuadrilla que aplica impulsos eléctricos a dementes para superar su enfermedad, pero realmente es una operación de tortura de presos políticos, siendo el error completamente evitable. Aquí no hay dudas sobre la negligencia de A pues quebranta exigencias de cuidado específicas a un siquiatra-funcionario público consistentes en, al menos, revisar los síntomas de los falsos pacientes. Ahora modifiquemos el caso, en el sentido que todo permanece igual, pero ahora $B$ es un funcionario que desempeña funciones de guardia en el recinto. Nótese que el estatus de funcionario público no reclama pertinencia para elaborar exigencias específicas de cuidado, por lo cual tenemos que acudir a exigencias generales de cuidado en la forma de imprudencia. Lo interesante es que, a pesar de la diferencia entre ambos ejemplos (que puede llegar a ser fundamental porque quizás para $\mathrm{B}$ el error no le resultaba evitable), el art. $150 \mathrm{~A}$ los engloba a ambos. El guardia del recinto - si afirmamos su imprudencia - no puede reclamar que actúa fuera de su ámbito profesional, pues la norma explícitamente, por medio de la referencia expresa a la negligencia y a la imprudencia, exige cuidado a todo funcionario público en toda situación.

De tal manera, este segundo grupo de normas también protege en forma amplísima un determinado bien jurídico, entendiéndose como 
normas especiales que se dirigen a un grupo de sujetos cualificados. Esto no quiere decir que aquellas normas que tipifican delitos especiales que solamente hacen referencia a la negligencia (y no a la imprudencia) protejan inadecuadamente los bienes jurídicos, sino que dada la descripción típica, la indicación de la imprudencia está fuera de lugar. Obsérvese el art. 224 que sanciona la prevaricación negligente: allí no es necesario acudir a la imprudencia pues lo que interesa es, precisamente, que sólo los jueces y fiscales judiciales queden obligados por las exigencias de cuidado que se derivan de su investidura. Que un funcionario del Registro Civil, por ejemplo, dictase imprudentemente una sentencia manifiestamente injusta no valdría como "dictar una sentencia”. El contenido de la descripción típica es la que sugiere los criterios específicos a utilizar en la imputación de la conducta que la infringe. En palabras simples: que el legislador indique conjuntamente (o no lo haga) imprudencia y negligencia dependerá de la configuración del delito respectivo.

\section{UNA PROPUESTA DE INTERPRETACIÓN PARA LOS CONCEPTOS DE DESCUIDO, IGNORANCIA Y ABANDONO}

Ahora bien, aún resta examinar otros tres conceptos que el legislador utiliza para el castigo de la falta de cuidado, a saber, el descuido, el abandono y la ignorancia.

a) En primer lugar, respecto del descuido, la propuesta es la siguiente: cuando una norma habla de $\mathrm{d}$ e s c u i d o entenderemos que se refiere, en todo caso, a n e g 1 i g e n c i a . Es decir, los conceptos de descuido y negligencia tienen el mismo contenido, de modo que son intercambiables. De tal modo, el descuido también opera como un criterio que determina la falta de cuidado de acuerdo al estatus especial del autor, el cual es relevante en el contexto preciso de actuación. Para justificar esta postura, se puede plantear tres argumentos.

Primero, ninguna norma del Código Penal alude, conjuntamente, tanto al descuido como a la negligencia. Evidentemente este argumento no es definitivo, pero un caso opuesto - o sea, si existiese una norma tal refutaría la tesis propuesta, pues habría que o bien aceptar que la norma es superflua en cuanto a declarar ambos criterios, o bien justificar que tienen un contenido diferente. En tal sentido, la propuesta no es inconsistente con la legislación.

Segundo, las normas que regulan los cuasidelitos contra las personas, en el Título X del Libro II, parecen estructurarse de acuerdo a criterios de falta de cuidado diferentes. Así, el art. 490 alude a la imprudencia temeraria y el art. 492 a la mera imprudencia o negligencia con infracción de 
reglamentos. Sin embargo, el art. 491 modifica la nomenclatura entre el primer y el segundo párrafo, ya que respecto de la praxis médica habla de $\mathrm{n}$ e glige n c i a y respecto a la tenencia de animales feroces habla de d e s c u i d o. Si asumimos que el legislador acudió a un mismo criterio por cada disposición, entonces podemos concluir que el descuido y la negligencia del art. 491 tienen el mismo contenido. Tal conclusión se acentúa al observar que se utiliza el mismo calificativo para ambos conceptos (negligencia c u l p a b l e en el inciso $1^{\circ} \mathrm{y}$ descuido $\mathrm{cul} \mathrm{p} \mathrm{a} \mathrm{b} \mathrm{l} \mathrm{e}$ en el inciso $2^{\circ}$ ).

Tercero, el Código Penal se refiere a la falta de cuidado en la praxis médica solamente en dos normas. La primera es el mencionado art. 491 inc. $1^{\circ}$, en donde la alusión a la negligencia es explícita. La segunda norma es el art. $494 \mathrm{n}^{\circ} 10$, en donde la referencia no es a negligencia sino a descuido. Si entendemos que ambas normas plantean la construcción de las reglas de imputación respectivas de la misma manera, entonces puede concluirse que tanto negligencia como descuido tienen el mismo contenido. Asimismo, vale la pena notar dos elementos adicionales que refuerzan la tesis: uno, ambas normas se refieren a los mismos sujetos activos: médico, cirujano, farmacéutico, flebotomiano ${ }^{41}$ y matrona; y dos, el art. 494 no 10 utiliza el mismo calificativo que el art. 491: descuido culpable.

Si bien ninguno de los tres argumentos es definitivo, entregan suficientes indicios para justificar la identificación entre la negligencia y el descuido. De ahí que cada norma que alude al descuido también señale un autor especial sujeto a determinadas exigencias de cuidado.

\section{Norma Capítulo Referencia EXPresa Sujeto especial}

Art. 302 De la evasión Cuando la evasión o Guardián (funciode los deteni- fuga de los presos o de- nario público que dos tenidos se efectuare por tiene confiada la descuido (...) conducción o custodia de los presos)

${ }^{41}$ Si bien el art. 494 no 10 habla de "dentista" en vez de "flebotomiano", como lo hace el art. 491, la doctrina nacional unánimemente identifica ambos conceptos. Véase, por todos, Garrido MontT, Mario, cit. (n. 5), I, p. 225. 
Art. 329 Crímenes y El que por ignorancia Empresario, direcsimples deli- culpable, impruden- tor o empleado del tos relativos a cia o descuido, o por ferrocarril ${ }^{42}$ ferrocarriles, inobservancia de los telégrafos y reglamentos del camiconductores no, que deba conocer, de correspon- causare involuntariadencia mente accidentes (...)

Art. 337 Crímenes y (...) al empleado que, Empleado de una simples delitos relativos a ferrocarriles, telégrafos $\mathrm{y}$ conductores de correspondencia

Art. 491 De los cuasidelitos

(...) al dueño de animales feroces que, por descuido culpable de su parte, causaren daño a las personas.
Dueño de animal feroz

b) Clarificado el concepto de descuido, restan la ignorancia y el abandono. Y resulta fundamental revisar atentamente las disposiciones que utilizan estos términos pues ello nos entrega herramientas para elaborar una adecuada interpretación. Así, cada vez que alguna norma del Código Penal se refiere a la ignorancia o al abandono también lo hace a la negligencia, es decir, las primeras nunca fundamentan por sí mismas la punibilidad de la falta de cuidado. De tal manera, puede proponerse lo siguiente: tanto ignorancia como abandono enfatizan un aspecto de la negligencia, es decir, están referidas a una manera específica de infracción de una exigencia especial de cuidado. Con esto no se pretende implicar que la referencia legislativa a los dos criterios sea redundante sino que es un refuerzo argumentativo para una correcta interpretación de la norma.

El concepto de a b a n d o n o solamente es utilizado en el art. 234 respecto de la malversación de caudales públicos negligente en los siguientes

${ }^{42} \mathrm{El}$ inciso primero del art. 329 no se refiere a sujeto especial alguno (utiliza "el que"), sin embargo el inciso final explicita que el artículo también es aplicable a "los empresarios, directores o empleados de la línea". De tal modo, mientras la imprudencia se relaciona con cualquier sujeto (con "los que"), el descuido lo hace con los sujetos señalados en el inciso final. 
términos: "el empleado público que por a b a ndo no o negligencia inexcusables, diere ocasión a que se efectúe por otra persona la sustracción de caudales o efectos públicos o de particulares (...)". En este sentido, el $\mathrm{a} b \mathrm{a} \mathrm{d}$ o $\mathrm{n}$ o se tiene que entender como la infracción de un deber de e j e c u c i ó n de la función pública que tiene el sujeto vinculado a una exigencia específica de cuidado. Es decir, la falta de cuidado pasa por no ejecutar la función que debía ejecutar, esto es, literalmente abandonarla. Esto se explica dada la concreta conducta que se sanciona, consistente en permitir (dar ocasión) a otro para que sustraiga caudales públicos. Ello implica que cuando el funcionario no desempeña (abandona) su función pública cuando le correspondía hacerlo, lo que posibilita la acción de sustracción de otro, infringe una exigencia de cuidado ${ }^{43}$.

Lo curioso es que la norma también alude a la negligencia, la cual se expresaría de una manera más general, como el desempeño i n a d e c u a d o de la función pública. Sin embargo, no desempeñar la función cuando debía hacerlo (abandono) también es una forma de desempeñar inadecuadamente esa función (negligencia), pero referido a un aspecto específico. De tal manera, el concepto de abandono no viene a modificar el contenido de la negligencia sino que acentúa lo igualmente sancionable de la mera no ejecución de las funciones públicas para evitar dar ocasión a la sustracción de otro.

Por otra parte, el concepto de i g n o r a n c i a se observa en cuatro normas, tres de las cuales se encuentran el capítulo de Prevaricación del Título V"De los crímenes o simples delitos cometidos por empleados públicos en el desempeño de sus cargos" y la cuarta es el ya examinado art. $329^{44}$. Aquí la i g n o r a n c i a tiene que ser entendida como la infracción de un deber de a d q u i s i c i ó n - y conservación - de conocimientos que tiene el sujeto

${ }^{43}$ Resulta interesante que el concepto de a b a n d o n o haga referencia a un comportamiento contrario al cuidado debido por no encontrarse (el funcionario público) en la posición que le correspondía. Esto evidencia que la imprudencia como criterio de imputación extraordinario no sólo se relaciona con un defecto cognitivo como en los casos más comunes - sino también con la misma incapacidad de acción, ya que el funcionario público - al "no estar" - estaba físicamente imposibilitado para evitar la realización típica y, por eso mismo, su conducta infringe las exigencias de cuidado específicas. Al respecto, véase REYEs, Italo, Un concepto, cit. (n. 4), pp. 146 ss.

${ }^{44}$ Dado que todas las normas pertinentes - a saber, arts. 224, 225, 228 y 329 - ya fueron citadas y explicadas previamente en las tablas correspondientes a la negligencia, no será necesario reiterarlas acá. Vale la pena recordar, eso sí, que tanto el art. 224 como el art. 225 están referidos a miembros de tribunales de justicia mientras que el art. 228 lo está a funcionario público que no pertenece al orden judicial. 
especial señalado en la norma. En tal sentido, la referencia a la ignorancia indica que la función pública desempeñada por el sujeto especial requiere ciertos conocimientos mínimos, y que su ignorancia implica la infracción de la exigencia de cuidado respectiva. Quien infringe tal exigencia se ve impedido de evitar, en el caso de la prevaricación, una sentencia manifiestamente injusta dado que carece de la preparación necesaria para dictar una sentencia conforme a derecho. Nótese que este deber de adquisición de conocimientos es especialmente relevante para quienes deben decidir conflictos penales o civiles de acuerdo al ordenamiento jurídico, puesto que el adecuado desempeño de la función exige una amplia instrucción y constante actualización de conocimientos. Sin embargo, de nuevo, carecer de los conocimientos necesarios para desempeñar la función pública respectiva también es una forma de desempeñar i $\mathrm{n}$ a d e c u a d a m e $\mathrm{n} t \mathrm{e}$ esa función pública, por lo tanto que la norma explicite el criterio de la ignorancia permite enfatizar legislativamente lo fundamental que resulta la adquisición de conocimientos para ese sujeto en particular.

\section{El APORTE DE LOS CALIFICATIVOS A LA IMPUTACIÓN A} TÍTULO DE IMPRUDENCIA

Si los criterios de imputación extraordinaria dicen relación con un determinado ámbito en que actúa un determinado sujeto y que configura las exigencias de cuidado relativas, los calificativos que los acompañan - a saber, temeraria, mera, inexcusable y culpableespecifican un grado o nivel de esas exigencias de cuidado. Ese argumento depende de que las exigencias de cuidado sean posibles de cuantificar, es decir, que se pueda reconocer medidas de precaución básicas y medidas de precaución calificadas ${ }^{45}$. Y ello se deja reconocer simplemente en la manera cotidiana que verificamos la falta de cuidado en un determinado contexto de actuación: el cirujano que olvida las tijeras quirúrgicas en el interior del paciente sufre un reproche cuantitativamente superior al de aquel cirujano que confunde el adecuado tratamiento quirúrgico porque los síntomas del tratamiento adecuado y del erróneo son especialmente similares. Ambos cirujanos actúan negligentemente porque infringen exigencias de cuidado, pero el primero infringe una exigencia mínima e incuestionable que, a todas luces, implicará que no pueda evitar las lesiones subsecuentes en el paciente ${ }^{46}$.

45 Esta es la opinión ampliamente dominante en la doctrina chilena. Véase, por todos, Couso, Jaime y Hernández, Héctor, cit. (n. 14), pp. 115 s.

${ }^{46}$ Es necesario clarificar que el hecho de que las exigencias de cuidado operen como criterio de una imputación extraordinaria, esto es, como el reconocimiento de 
A este respecto, es favorable analizar pares conceptuales de calificativos en la forma de temeraria/mera e inexcusable/culpable. Esto porque el segundo par está inequívocamente relacionado con la negligencia o descuido, mientras que la aplicación del primero es general.

a) El calificativo de t e m e r a ria sólo se utiliza acompañando a la imprudencia en los artículos 317 y 490 . De tal forma, lo temerario se conecta con el grado máximo de falta de cuidado, en la forma de una infracción de exigencias de cuidado básicas. Bustos entiende que la imprudencia temeraria "trata entonces de no aplicar aquel cuidado que aun una persona poco prudente aplica en relación a sus propios bienes jurídicos importantes" ${ }^{\prime 7}$, o sea, se trata de infringir el cuidado que hasta el imprudente podría reconocer. En tal sentido, para que prospere la imputación a título de imprudencia temeraria no sólo se requiere justificar un quebrantamiento de las exigencias de cuidado sino también que ese quebrantamiento conlleve precisamente la falta del cuidado mínimo exigido en un determinado contexto de actuación $\mathrm{n}^{48}$.

En la jurisprudencia es posible inferir que se ha descartado la temeridad de la imprudencia cuando la víctima también se comportó de manera descuidada, sin necesidad de negar la falta de cuidado predicable del autor, sino argumentando que la intervención descuidada del sujeto pasivo conlleva que tal imprudencia no fuera suficiente para ser entendida como temeraria ${ }^{49}$.

una capacidad de evitación supletoria a la imputación a título de dolo, no implica que éstas no puedan ser clasificadas en atención a su gravedad. Lo que el Código Penal exige es un juicio de valor adicional de intensidad, pues ya se ha determinado que existe falta de cuidado al infringir una exigencia de cuidado respectiva; lo que interesa ahora es evaluar si esa exigencia de cuidado era tan básica que corresponde afirmar que el sujeto se ha comportado temerariamente. Por ende, el juicio de determinación de la imprudencia y el juicio de su gravedad son autónomos entre sí.

47 Bustos, Juan, cit. (n. 14), p. 50, quien la relaciona con la culpa grave en materia civil (art. 44 Código Civil)

${ }^{48}$ En el mismo sentido, Garrido Montt, Mario, cit. (n. 5), I , p. 224; Politoff, Sergio - Matus, Jean Pierre - Ramírez, María Cecilia, cit. (n. 15), p. 291; y FernÁndeZ CruZ, José Ángel, cit. (n. 10), p. 112. Por su parte, CorCoy, Mirentxu, cit. (n. 3), pp. 360 s. sostiene que la imprudencia temeraria apunta a que "se infrinjan elementales deberes exigibles a la persona cuidadosa", pero luego agrega que el elemento subjetivo del deber de cuidado (que ella denomina "cognoscibilidad") también influye en el determinación de la intensidad de la infracción de dicho deber.

${ }^{4}$ Así puede entenderse en Sentencia de la Corte Suprema, contra Ruiz Ulloa, Revista de Derecho y Jurisprudencia, tomo LXX (1973), vol. 4, p. 88, en ETCHEBERRY, Alfredo, El derecho penal en la jurisprudencia (sentencias 1875-1966) (Santiago, Editorial Jurídica, 2002), IV, p. 564; y en Sentencia de la Corte de Apelaciones de Pedro Aguirre Cerda, Contra Alarcón Martínez y otro, Revista de Derecho y 
Por contrapartida, la exigencia de m e $\mathrm{r}$ a imprudencia o negligencia se entendería como una forma menos grave que la temeraria, y que Bustos la entiende como "la falta de cuidado medio exigido en un ámbito de relación, hay un mayor grado de exigencia" ${ }^{50}$. En otras palabras, es la infracción de exigencias de cuidado que un observador promedio - con los conocimientos específicos del autor - entiende como adecuadas al contexto. Es decir, se corresponde con la definición estándar de falta de cuidado. Este calificativo se observa en los artículos 317 y 492, pero con significativas diferencias entre ambos pues mientras el art. 492 se refiere tanto a la mera imprudencia como a la mera negligencia, el 317 sólo lo hace respecto de la segunda.

Ahora bien, si la mera negligencia o imprudencia no se diferencia del concepto general de falta de cuidado, la pregunta es por qué el legislador incorpora el calificativo mera. Y la respuesta se deja descubrir examinando con detención las normas del Código Penal: el señalamiento expreso de m e r a imprudencia o negligencia sólo se realiza allí donde es necesario contraponerlo a una superior falta de cuidado, o sea, un quebrantamiento de una exigencia de cuidado mínima. Es decir, la $\mathrm{m}$ e $\mathrm{r}$ a negligencia o imprudencia enfatiza que no estamos hablando de una falta de cuidado calificada. Esto se comprueba revisando los artículos 243 y 333, los cuales carecen del calificativo en estudio porque no existe ninguna norma ulterior relativa que haga necesaria su indicación explícita. Por el contrario, el art. 317 hace referencia, junto a la mera negligencia, a la imprudencia temeraria; y el art. 492 se relaciona directamente con los arts. 490 y 491 que también responden a formas calificadas de falta de cuidado. En tal sentido, las nociones de m e r a i m p r u d e n c i a y de imprudencia son sustancialmente equivalentes, pero el legislador utiliza la primera cuando considera que debe reforzar su contenido frente a otro término cuantitativamente superior.

Así la mera imprudencia o negligencia del art. 492 sería de una gravedad menor en comparación con la imprudencia temeraria del art. 490, lo cual

Jurisprudencia, tomo LXXIX (1982), vol. 4, p. 136; en ETCHEBERRY, Alfredo, El derecho penal, cit. (n. 50). En el primer caso, se absolvió a la imputada por la muerte de una mujer, con la que tenía un altercado, ocasionada por una caída que ella (la imputada) provocó; y en el segundo caso, también se absolvió a un grupo de sujetos que perseguían a intrusos en una propiedad, los cuales en virtud de la persecución cayeron a un foso y murieron.

${ }^{50}$ Bustos, Juan, cit. (n. 14), p. 51, asimilándola a la culpa leve en materia civil. En el mismo sentido, Garrido Montt, Mario, cit. (n. 5), I, p. 224 y Politoff, Sergio - Matus, Jean Pierre - Ramírez, María Cecilia, cit. (n. 15), p. 292. 
se compensa por la exigencia adicional de infracción reglamentaria ${ }^{51}$. Este requisito adicional es relevante al momento de entender que el quebrantamiento de reglamentos no fundamenta, p e $\mathrm{r}$ s e, la falta de cuidado sino que sólo permite reconocerla con mayor facilidad.

b) Por su parte, los términos c u l p a b l e e i n e x c u s a b l e aluden indistintamente a los criterios de negligencia o descuido que conllevan exigencias especiales de cuidado, observándose las combinaciones de negligencia inexcusable (arts. 224, 225, 228, 229 y 234), descuido culpable (arts. 302, 337, 491 inc. $2^{\circ}$ y $494 \mathrm{~N}^{\circ} 10$ ) y negligencia culpable (art. 491 inc. $1^{\circ}$ ). A este respecto seguiremos el criterio de Bustos quien señala que "culpable e inexcusable significan entonces no haber aplicado ni siquiera el cuidado mínimo requerido para el cumplimiento de un deber, y precisamente por esa falta de cuidado es culpable e inexcusable" ${ }^{" 52}$. De tal modo, estos términos explicitan una infracción grave de la exigencia de cuidado o, que es lo mismo, el quebrantamiento de una exigencia básica de cuidado por aquellos que especialmente quedan vinculados a éstas. Es por tanto la forma equivalente a la imprudencia temeraria, pero en el ámbito de la negligencia ${ }^{53}$.

Ahora bien, la diferencia conceptual entre i n e $\mathrm{cus}$ a ble y cul$\mathrm{p}$ a b l e no resulta demasiado clara pero entendiendo que la negligencia o ignorancia inexcusable hace, en general, referencia a un funcionario público (prevaricación - arts. 224, 225, 228 y 229 - y malversación de caudales públicos - art. 234), podemos postular que lo i n e x c u s a b l e se relaciona con exigencias de cuidado institucionalmente reglamentadas, en este caso por medio de una ley. Por el contrario lo culpable se

${ }^{51}$ Mañalich, Juan Pablo, Condiciones, cit. (n. 20), p. 416. Resulta sumamente interesante la crítica que realiza Fernández CruZ, José Ángel, cit. (n. 10), p. 112 s., a la equiparación que realiza el Código Penal entre mera negligencia profesional (con infracción de reglamentos) e imprudencia temeraria, pues la infracción de los reglamentos no supone un aumento de la gravedad de la infracción de cuidado sino solamente un indicio de ella.

52 Bustos, Juan, cit. (n. 14), p. 55 s. Explica Bustos que "con razón el legislador no utiliza la voz temeraria en este caso, pues el no cumplimiento de un deber no puede adjetivarse como temerario si se le quiere dar una gran gravedad, sino precisamente de culpable o inexcusable".

53 En el mismo sentido, Politoff, Sergio - Matus, Jean Pierre - Ramírez, María Cecilia, cit. (n. 15), p. 293. En contra, Fernández Cruz, José Ángel, cit. (n. 10 ), p. 112, quien entiende que resulta más grave la negligencia inexcusable que la negligencia culpable, aunque no profundiza en las razones de dicha clasificación. La discusión completa de la doctrina chilena al respecto puede ser revisada en Couso, Jaime y HernándeZ, Héctor, cit. (n. 14), p. $115 \mathrm{~s}$. 
relacionaría con exigencias de cuidado específicas pero no contenidas en un cuerpo normativo obligatorio, por ejemplo la lex artis médica.

\section{RECAPITULACIÓN}

La apertura a la punibilidad de la falta de cuidado en el Código Penal se realiza en atención a cinco conceptos precisos utilizados por el legislador. Entre ellos, tanto por razones cuantitativas (se usan con más habitualidad) como cualitativas (parecen ser la base de los demás términos) destacan la negligencia y la imprudencia. Tomando en cuenta la redacción específica de las disposiciones, parece sensato sostener que, primero, la negligencia apunta una exigencia de cuidado específica, pues se refiere a un sujeto con un estatus especial que resulta relevante de acuerdo al contexto; y segundo, la imprudencia está referida a las exigencias de cuidado generales predicables de cualquier sujeto.

No obstante, en un ámbito importante de aplicación, el legislador no sólo acude a los conceptos de falta de cuidado sino que hace alusión también a la infracción de reglamentos. Si bien la mera infracción puede ya tener relevancia en un contexto administrativo-sancionador, es fundamental insistir en que dicha infracción de reglamentos sólo puede operar como un indicio de la responsabilidad penal a título de imprudencia. Pues los reglamentos determinan el riesgo socialmente tolerado en situaciones cotidianas, de manera que sólo tienen una influencia tangencial en el proceso de adjudicación al definir si el autor ha infringido (o no) la exigencia de cuidado correspondiente.

Para terminar, una brevísima crítica. Desde hace un par de décadas, la doctrina nacional ha comenzado a estudiar con mucha profundidad las problemáticas teóricas de la imprudencia. Sin embargo, las específicas disposiciones de nuestra legislación que apuntan a dicha punibilidad no han sido revisadas con el mismo ahínco. Es totalmente cierto que el ámbito de estudio de la imprudencia es amplísimo y que está relacionado con otras esferas de la teoría del delito que, por supuesto, escapan a la regulación legal. Sin embargo ello no debiera significar dejarla de lado. Sigue siendo cierto que, en ocasiones, el Código Penal no parece terminológicamente coherente, empero es labor del intérprete otorgar contenido armónico a los enunciados provistos por ley, preocupándose especialmente de evitar reiteraciones y conceptos vacíos, con el propósito de consolidar una importante máxima: el legislador es sistemáticamente coherente. 


\section{BiBLIOGRAFÍA}

Bustos, Juan, El delito culposo (Santiago, Editorial Jurídica, 2006).

Corcoy, Mirentxu, El delito imprudente. Criterios de imputación del resultado (2a edición, Montevideo/Buenos Aires, BdeF, 2005).

Couso, Jaime y Hernández, Héctor, Código Penal comentado. Libro Primero (arts. $1^{o}$ a 105). Doctrina y Jurisprudencia (Santiago, LegalPublishing, 2011).

CurY, Enrique, Derecho penal, parte general (7a edición, Santiago, Ediciones Universidad Católica, 2005).

Etcheberry, Alfredo, Derecho Penal (3a edición, Santiago, Editorial Jurídica, 1997).

EtCHEBERry, Alfredo, El derecho penal en la jurisprudencia (sentencias 1875-1966) (Santiago, Editorial Jurídica, 2002).

FEIjoo, Bernardo, Resultado lesivo e imprudencia. Estudios de los límites de la responsabilidad penal por imprudencia y el criterio del "fin de protección de la norma de cuidado" (Barcelona, Bosch, 2001).

FernÁndez Cruz, José Ángel, El delito imprudente: la determinación de la diligencia debida en el seno de las organizaciones, en Revista de Derecho, vol. XIII (2002).

Garrido Montt, Mario, Derecho Penal. Parte Especial (4a edición, Santiago, Editorial Jurídica, 2005).

HruSCHKA, Joachim, "Reglas de comportamiento y reglas de imputación”, ahora, en el Mismo, Imputación y Derecho Penal (Montevideo/ Buenos Aires, B de F, 2009).

HRUSCHKA, Joachim, La imputación ordinaria y extraordinaria en Pufendorf, ahora, en el Mismo, Imputación y Derecho Penal (Montevideo/ Buenos Aires, B de F, 2009).

KINDHÄUSER, Urs, El tipo subjetivo en la construcción del delito, en InDret 4 (2008)

KInDHÄUSER, Urs: ¿Qué es la imprudencia?, ahora, en MAÑALICH (dir.), La ciencia penal en la Universidad de Chile. Libro homenaje a los profesores del departamento de ciencias penales de la Facultad de Derecho de la Universidad de Chile (Santiago, Facultad de Derecho, Universidad de Chile, 2013).

Mañalich, Juan Pablo, Condiciones generales de la punibilidad, en Revista de Derecho de la Universidad Adolfo Ibáñez, nº 2 (2005).

MaÑALICH, Juan Pablo, El delito como injusto culpable. Sobre la conexión funcional entre el dolo y la consciencia de la antijuridicidad en el derecho penal chileno", en Revista de Derecho vol. XXIV (2011).

Mañalich, Juan Pablo, Norma e imputación como categorias del hecho punible, en Revista de Estudios de la Justicia 12 (2010).

NovoA, Eduardo, Curso de derecho penal ( $3^{a}$ edición, Santiago, Editorial Jurídica, 2005).

Ovalle, Germán, Imprudencia y cognición, en Doctrina y jurisprudencia penal $\mathrm{n}^{\circ} 4$ (2011).

Pérez del Valle, Carlos, La imprudencia en el derecho penal. El tipo subjetivo del delito imprudente (Barcelona, Atelier, 2012).

Politoff, Sergio - Matus, Jean Pierre - Ramírez, María Cecilia, Lecciones de derecho penal chileno (2a edición, Santiago, Editorial Jurídica, 2004).

Ragués i Valles, Ramón, El dolo y su prueba en el proceso penal (Barcelona, Bosch Editor, 1999).

ReYes Romero, Italo, Un concepto de riesgo permitido alejado de la imputación objetiva, en Ius et Praxis año 21, no 1 (2015). 
Reyes Romero, Italo, Sobre la construcción de la exigencia de cuidado, en Política Criminal vol. 10 no 19 (2015).

Reyes Romero, Italo, El cuasidelito con resultado múltiple, en El derecho penal como teoría y como práctica. Libro en homenaje al profesor Alfredo Etcheberry (Santiago, Thomson Reuters, 2016).

Rosas, Juan Ignacio, La delimitación del deber de cuidado en la imputación de responsabilidad penal por imprudencia médica, en Doctrina y jurisprudencia penal $\mathrm{n}^{\circ} 5$ (2011). Disponible en LegalPusblishing on line: CL/DOC/1210/2013.

VAN WeEzel, Álex, El dolo eventual como espacio de discrecionalidad, en Doctrina y Jurisprudencia Penal Vol. VII (2012). Disponible en: LegalPublishing on line, Cita CL/DOC/1203/2013 [visitado el 24/09/2014].

Van Weezel, Álex, Parámetros para el enjuiciamiento de la infracción al deber de cuidado en los delitos imprudentes, ahora, en el mismo, Limites de la imputación penal. Estudios 2000-2010 (Bogotá, Universidad Externado de Colombia, 2011). 